Cumhuriyet International Journal of Education-CIJE

\title{
Geography Teacher Candidates' Opinions On FATIH Project
}

\author{
Abdullah TÜRKER
}

\section{Summary}

\section{INTRODUCTION}

Technological advancements become more active in educational activities as in every instant of our lives. Hence the amount of investment on technological infrastructure of schools and educational activities along with improvement of equipment increase gradually. At this point, according to the objective 'Ensuring all schools make use of information technologies by the end of 2014 providing the regional discrepancies be abolished among all of the subsidiary schools and institutions of the Ministry of National Education' stated in the 20102014 strategic plan of the Ministry of National Education, FATIH project came into force in 2011-2012 academic year which was piloted in 52 schools in 17 provinces. Within the context of the project, it is planned that all classrooms will be provided with interactive boards and all students and teachers will be handed out tablets. Along with distribution of interactive boards and tablets, e-book and content development works are continuing. As part of the project, it is planned that 675.000 teachers and students will be provided with tablets as of end of March 2014 (MEB, 2014). In this research, it is aimed to identify opinions of geography teacher candidates on FATIH project. By this means it is aimed to find out teacher candidates' views, who will participate in conduct of the project on issues like their perspectives on the project, applicability of the project across the country, positive and negative aspects of the project regarding teachers and students and effects of the project on geography lessons. The study was conducted between 2013 and 2015 with 92 teacher candidates studying in the department of Geography Education in Gazi University, Gazi Faculty of Education.

\section{METHOD}

Data of this research, which follows qualitative research methodology were collected by means of an open ended questionnaire developed by the researcher by thorough examination of the issues discussed in the literature and finalized after manipulations suggested by experts. Moreover, 2 of each class level and with cumulative GPAs over $3.00 / 4.00$, total of 8 students were interviewed. Content analysis procedures were followed in analysis of the data collected. Data obtained from written documents and interviews were coded and categories and themes were attained. Prevalence and percentages of the codes were calculated. Both qualitative and quantitative (frequencies and percentages) data were interpreted together. For validity and reliability, another expert of the field was asked to analyze the research data. Codes and themes obtained by the researcher and the expert were compared and found significant similarity between the two. Together with this, findings of the research were presented to the participants and their confirmations were acquired. Direct citations were made to the participants' statements in the tables created by the results of data analyses.

\section{RESULTS}

$44.5 \%$ of the participant geography teacher candidates think that the FATIH Project would contribute to the technology using skills of students and that the Project will have positive impact on the quality and effectiveness of the education. More than half of the participants indicated that the Project is important and essential to keep pace with technology. Some candidates however, indicated that the project is inessential because it is intimidating, is 
likely to make people free-riding and may detract from books. Candidates hold the idea that the project cannot be implemented equivalently throughout the country because of regional economical and geographical disparities, and even though it is implemented, utilization will be different because of student readiness differences across the country. Participants have the opinion that the project will not have any negative effect on the geography lesson. All of the participants stated that the project will be more beneficial on teaching of the physical geography lesson subjects like geographical formations, internal and external forces, climate, map information, shape and movements of the earth. $47.8 \%$ of the participant teacher candidates consider senior teachers currently working in educational institutions as an obstacle in implementation of the project because they lack necessary technological skills.

\section{DISCUSSION AND IMPLICATIONS}

Starting out from the findings of the research, two important factors that geography teacher candidates arrived at consensus in successful implementation of the FATIH project which will give remarkable acceleration to educational achievements are elimination of the infrastructural shortages and training of teachers and students. Within this context, prolongation of the pilot implementation period, increasing the number of pilot schools and continuous revising by taking teacher-student-parent feedback in consideration are crucial in successful implementation of the project. In success of the project, it is important to increase knowledge and skills competencies of teachers who are the executers of the project by inservice training programs about the project and of the teacher candidates who will be involved in the process in the future by including necessary subjects in the university curriculum. Geography teacher candidates in particular and all prospective teachers in general need to be provided necessary training during the undergraduate studies on development of applications for interactive boards and tablets. E-contents offered for use of teachers and students via Education Information Technologies Network (EBA) which is a subcomponent of the project should be enriched and updated. 